\title{
The immunological effects of trauma
}

\author{
BY T. W. J. LENNARD AND D. A. BROWELL \\ Department of Surgery, The Medical School, The University, Newcastle upon Tyne NE2 4HH
}

Trauma, both surgical as occurs during an elective operation, and accidental as in the burn or road traffic accident victim, is associated with a relative state of immunosuppression. Why this apparently deleterious response should happen remains unexplained, but our understanding of the interactions within the immune system during trauma is increasing dramatically. The use of monoclonal antibodies, recombinant DNA technology and highly sensitive assays has permitted the dissection of much of the immune system to be carried out. The present review will examine recent findings on the immunological consequences of trauma.

For many years surgeons have been aware that patients who have short, uncomplicated operations recover much quicker than those who have lengthy, complex procedures (Buckman, 1976). The metabolic (Gill et al. 1975) and endocrine (Johnston, 1972) responses to trauma are well known. Recent interest in the immune system (which has an important role in response to infection, allograft rejection and probably malignancy) and trauma has developed because of the exciting possibility of using drugs or cytokines to block or augment certain immunological events.

The immunological response can be seen as an orderly progression of cellular activity and protein production to control injury and modulate healing. This includes haemostasis, production of growth factors, changes in the microcirculation, the inflammatory response and wound repair. The inflammatory response can be subdivided into an innate response and an adaptive one. The innate response includes such factors as secreted enzymes and proteins, acute-phase proteins, activation of the alternate pathways of complement, the interferons (IFN) and non-specific immunological activity such as phagocytosis and natural killer (NK) cell activity. None of the factors previously described require previous 'programming' or cooperation with specific antigen-primed cells to be effective.

The adaptive immune response, in contrast, is a highly specific response occurring as a result of directed antibodies, targeted cytokine-mediated lymphocyte activity and the classical pathway of complement activation (Lennard, 1991). The typical cascade reaction to antigen is shown in Fig. 1.

The observation that critically ill postoperative patients often have measurable deficiencies in components of their immune system (McIrvine \& Mannick, 1983) led logically to the assumption that detection of these deficiencies might (a) be predictive of complications before they occur and (b) be preventable or reversible.

Changes in the number and function of T-lymphocytes (Hansborough et al. 1984; Lennard et al. 1985), NK cells (Lennard et al. 1985; Tonnesen, 1989) and the cytokines (Faist et al. 1987) and receptors (Akiyoshi et al. 1985; Teodorczyk-Injeyan et al. 1987) that control these important immune effector cells do occur postoperatively and generally the effect of trauma is to down regulate these cells, thus rendering the patient comparatively immunosuppressed.

The expression of class II major histocompatibility complex (MHC) on monocytes (a 


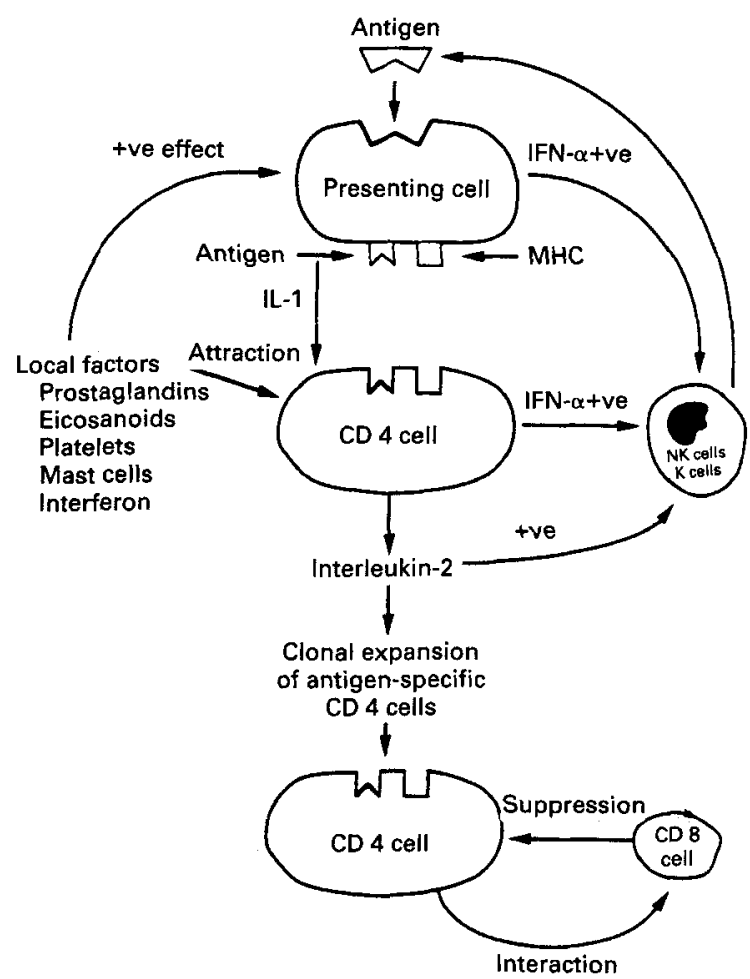

Fig. 1. Cascade reaction to antigen. IFN, interferon; NK, natural killer; Il, interleukin; MHC, major histocompatibility complex; K, killer; $\mathrm{CD}$, cluster differentiation.

prerequisite for effective antigen presentation and processing) is diminished in trauma patients and can assist in identifying those who go on to develop infective complications (Hershman et al. 1990; Cheadle et al. 1991). Defects in neutrophil chemotaxis, phagocytosis, lysosome activity and superoxide production have been identified postoperatively (Utoh et al. 1988), in addition to increased prostaglandin $\mathrm{E}_{2}$, defective monocyte interleukin (IL)- 1 secretion, and diminished IFN- $\gamma$ production (Faist et al. 1988). There is evidence that administration of IFN- $\alpha$ preoperatively can abrogate reduced postoperative NK cell activity in patients with gastrointestinal malignancy (Sedman et al. 1988), and that IFN- $\gamma$ may correct some of the immunological disturbances associated with severe injury and reduce septic complications (Polk et al. 1992).

The cytokines regarded as major mediators of the acute-phase response are tumour necrosis factor (TNF), IL-1 and IL-6. TNF and IL-1 produce clinical signs of the acute-phase response (fever, tachycardia and catabolism) as a 'side effect' of their activity on CD 4 cells and their interaction with other cytokines, notably IL-6 (Kohase et al. 1986; Bauer et al. 1988; Tosatu \& Jones, 1990). IL-1, IL-6 and TNF probably all contribute to produce the synthesis of the acute-phase proteins (Baumann \& Gauldie, 1990). IL-6 is elevated postoperatively in elective surgical patients (Shenkin et al. 1989; Cruickshank et al. 1990), but IL-1 and TNF responses are less clear (Pullicino et al. 
1990). Some evidence does exist, however, for a poor outcome in septic or burnt (Debets et al. 1989) patients who have high levels of TNF or IL-6 (Damas et al. 1992; Ohzato et al. 1992).

Finally, in addition to trauma itself, the effects of blood transfusion must be considered. Haemorrhage alone causes a depression of the immune system (Stephan et al. 1987; Ayala et al. 1990) and blood transfusions, too, have been associated with immune depression, increased sepsis and a poor outcome after surgery (Jensen et al. 1992).

The contribution towards immunosuppression by perioperative blood transfusion (POBT) remains controversial. One of the difficulties is the separation of the potential immunosuppressive activities of POBT from those of haemorrhage or coexistent disease. It is known that transfusion of blood can render T-lymphocytes unable to recognize major histocompatibility antigens expressed on a grafted organ that has similar antigens to the transfused blood (Vantwuyver et al. 1991). This specific immunosuppression has been exploited in both experimental and clinical organ transplantation. However, it is difficult to draw clear parallels between allograft specific immunosuppression and the more generalized, non-specific immunosuppression associated with trauma.

In animal models haemorrhage in the absence of any other trauma has been shown to decrease immunological resistance to a bacterial challenge (Stephan et al. 1987; Livingston \& Malangoni, 1989). Similarly tumours have an increased growth rate in animals subjected to hypovolaemia and lymphocytes from these animals exhibit a decreased response to non-specific stimulation by mitogens (Younes et al. 1991). Blood transfusion in the absence of significant hypovolaemia also increases the animal's susceptibility to bacterial infection (Galandiuk et al. 1990).

Clinical studies have shown that neonatal recipients of exchange transfusions have a decreased lymphocyte responsiveness for at least two decades after the transfusion (Beck et al. 1981). Patients who have required transfusion because of anaemia secondary to inflammatory bowel disease have significant reductions in their total numbers of T-cells for up to 18 months (Tartter et al. 1986). Laboratory studies have shown that a blood transfusion decreases NK cell and macrophage function as well as decreasing the helper/suppressor T-cell ratio (Kaplin et al. 1984; Waymack et al. 1987, 1990), and these effects appear to be additive to the immunosuppressive effect of trauma, increasing the infective complications (Waymack et al. 1986; Pinto et al. 1991). Furthermore, these effects appear to be proportional to the size of the transfusion (Tartter, 1989). IFN- $\gamma$ can attenuate haemorrhage-induced immunosuppression and susceptibility to sepsis (Ertel et al. 1992). The use of autologous blood is under investigation to determine whether it can avoid the observed effects of third-party blood. Recent work suggests that the 'blood transfusion' effect may be related to its storage before transfusion, during which time the cellular elements of blood become senescent and die releasing many potential biologically active compounds (Lawrance et al. 1990). In vitro the supernatant fraction from stored blood inhibits the response of autologous lymphocytes to mitogenic stimuli as well as promoting malignant cell proliferation (Browell et al. 1992). Predeposit autologous blood is stored for up to 4 weeks before its use and is subject to the same aging process. Thus, if these in vitro effects are repeated in vivo, the use of predeposit autologous blood would not confer any immunological benefit over third-party blood. Clinical studies supporting these results indicate that predeposit autologous blood does not abrogate infective complications which occur with the use of third-party blood in elective colo-rectal surgery (Busch et al. 1992). 
The use of intraoperative autotransfusion from 'clean surgical cases' does not increase the risk of septic complications (Ezzedine et al. 1991). The use of blood salvaged from potentially contaminated surgical fields has always been contraindicated, but it may have a role as washing and filtration of salvaged blood removes damaged cells, cell debris, malignant cells, as well as bacteria (Miller et al. 1991; Ozmen et al. 1992), and activated components of the complement cascade (Sieunarine et al. 1991).

The use of drugs has been suggested as a way of overcoming POBT immunosuppression. Ranitidine appears to prevent the decrease in delayed hypersensitive immunoreactivity observed in recipients of POBT (Neilsen et al. 1989). Indomethacin, a prostaglandin synthase (EC 1.14.99.1) inhibitor, has also been shown to inhibit transfusion-induced immunosuppression (Shelby et al. 1987). The links between blood transfusion and a patient's immune system are not merely related to an increase in infective complications or cancer recurrence, as there is now evidence to suggest that blood transfusions impair healing directly by increasing rates of intestinal anastomotic dehiscence (Tadros et al. 1992).

\section{CONCLUSION}

What are the clinical implications of the effects described above?

1. There appears to be a 'dose-response effect' of trauma on the immune system. The bigger and longer lasting the injury, the greater the immune depression. Perhaps the dramatic recovery seen after laparoscopic surgery compared with the more traumatic open operations can be explained by this. Surgical trauma should, therefore, be reduced to an absolute minimum and more emphasis placed on perfecting minimally invasive surgery.

2. The magnitude of immunological disturbance may predict for complications.

3. Haemorrhage alone induces immune depression; therefore, care should be taken to minimize this, and techniques developed to reduce blood loss to a minimum.

4. Blood transfusions cause immunosuppression and are implicated in several postoperative complications. Thus, they should be used only according to strict indications.

5. Research should continue to dissect further the effects of trauma on the immune system, and ways to overcome this biologically or pharmacologically.

\section{REFERENCES}

Akiyoshi, T., Koba, F., Aringa, S., Miyazaki, S., Wada, T. \& Tsuji, H. (1985). Impaired production of interleukin-2 after surgery. Clinical \& Experimental Immunology 59, 45-49.

Ayala, A., Perrin, M. M., Wagner, M. A. \& Chaudry, I. H. (1990). Enhanced susceptibility to sepsis after simple haemorrhage: depression of Fc and C3b receptor-mediated phagocytosis. Archives of Surgery 125, 70-75.

Bauer, J., Ganter, U., Geiger, T., Jacobshagen, U., Hirano, T., Matsuda, T., Kishimoto, T., Andus, T., Acs, G., Gerok, W. \& Cilberto, G. (1988). Regulation of interleukin-6 expression in cultured human blood monocytes and monocyte-derived macrophages. Blood 72, 1134-1140.

Baumann, H. \& Gauldie, J. (1990). Regulation of hepatic acute phase plasma protein genes by hepatocyte stimulating factors and other mediators of inflammation. Molecular \& Biological Medicine 7, 147-159.

Beck, T., Scott, J. S. \& Pepper, M. (1981). The effect of neonatal exchange and later blood transfusions on lymphocyte cultures. American Journal of Reproductive Immunology 1, 224-225.

Browell, D. A., Kirby, J. A., Shenton, B. \& Lennard, T. W. J. (1992). Is autologous blood superior to third party blood during cancer surgery? British Journal of Cancer 66, Abstr., 4.

Buckman, R. F. (1976). Lord Moynihan of Leeds. Surgery, Gynaecology \& Obstetrics 142, $90-914$. 
Busch, O. R. C., Hoynck van Papendrecht, M. A. W., Marquet, R. L. \& Jeekel, J. (1992). Gut 33, S70Abstr. Cheadle, W. G., Hershman, M. J., Welhausen, S. R. \& Polk, H. C. (1991). HLA-DR antigen expression on peripheral blood monocytes correlates with surgical infection. American Journal of Surgery 161, 639-645.

Cruickshank, A. M., Fraser, W. D., Burns, H. J. G., van Damme, J. \& Shenkin, A. (1990). Response of serum interleukin-6 in patients undergoing elective surgery of varying severity. Clinical Science 79, $161-165$.

Damas, P., Ledoux, D., Nys, M., Vrindts, Y., Degroote, D., Franchimont, P. \& Lamy, M. (1992). Cytokine serum level during severe sepsis - human Il-6 as a marker of severity. Annals of Surgery 215, 356-362.

Debets, J. M. H., Kampmeijer, R., van der Linden, M., Buurman, W. A. \& van der Linden, C. J. (1989). Plasma tumour necrosis factor and mortality in critically ill septic patients. Critical Care Medicine 17, 489-494.

Ertel, W., Morrison, M. H., Ayala, A., Dean, R. E. \& Chaudry, I. H. (1992). Interferon attenuates haemorrhage induced suppression of macrophage and splenocyte functions and decreases susceptibility to sepsis. Surgery 111, 177-187.

Ezzedine, H., Baele, P. \& Robert, A. (1991). Bacteriologic quality of intraoperative autotransfusion. Surgery $109,259-264$.

Faist, E., Mewes, A., Baker, C. C., Strasser, T., Alkan, S. S., Rieber, P. \& Heberer, G. (1987). Prostaglandin $\mathrm{E}_{2}\left(\mathrm{PGE}_{2}\right)$-dependent suppression of interleukin-2 (IL-2) production in patients with major trauma. Journal of Trauma 27, 837-847.

Faist, E., Mewes, A., Strasser, T., Walz, A., Alkan, S., Baker, C., Ertel, W. \& Heberer, G. (1988). Alteration of monocyte function following major injury. Archives of Surgery 123, 287-292.

Galandiuk, S., George, C. D., Pietsch, J. D., Byck, D. C., DeWeese, R. C. \& Polk, H. C. (1990). An experimental assessment of the effect of blood transfusion on the susceptibility to bacterial infection. Surgery 108, 567-571.

Gill, G. V., Prudhoe, K., Cook, D. B. \& Latner, A. L. (1975). Effect of surgical trauma on plasma concentrations of cyclic AMP and cortisol. British Journal of Surgery 62, 441-443.

Hansborough, J. F., Bender, E. M., Zapata-Sirvent, R. \& Anderson, J. (1984). Altered helper and suppressor lymphocyte in surgical patients: a measure of postoperative immunosuppression. American Journal of Surgery 148, 303-307.

Hershman, M. J., Cheadle, W. G., Welhausen, S. R., Davidson, P. F. \& Polk, H. C. (1990). Monocyte HLA-DR antigen expression characterises clinical outcome in the trauma patient. British Journal of Surgery 77, 204-207.

Jensen, L. S., Anderson, A. J., Christiansen, P. M., Hokland, P., Juhl, C. O., Madsen, G., Mortensen, J., Møller-Nielsen, C., Hanberg-Sørensen, F. \& Hokland, M. (1992). Postoperative infection and natural killer cell function following blood transfusion in patients undergoing elective colorectal surgery. British Journal of Surgery 79, 513-516.

Johnston, 1. D. A. (1972). The endocrine response to trauma. Advances in Clinical Chemistry 15, $255-285$.

Kaplin, J., Sarnaik, S., Gitlin, J. \& Lusher, J. (1984). Diminished helper/suppressor lymphocyte ratio and natural killer cell activity in recipients of repeated blood transfusions. Blood 64, 308-310.

Kohase, M., Henriksen-DeStefano, D., May, L. T., Vilcek, J. \& Sehgal, P. (1986). Induction of beta 2-interferon by tumour necrosis factor: a homeostatic mechanism in control of cell proliferation. Cell 45, $659-666$

Lawrance, R. J., Cooper, A. J., Loizidou, M., Alexander, P. \& Taylor, I. (1990). Blood transfusion and recurrence of colorectal cancer: the role of platelet derived growth factors. British Journal of Surgery 77 , 1106-1109.

Lennard, T. W. J. (1991). Regulation of the immune response. In Immunology in Surgical Practice. London: Edward Arnold.

Lennard, T. W. J., Shenton, B. K., Borzotta, A., White, M., Gerrie, L. M., Proud, G. \& Taylor, R. M. R. (1985). The influence of surgical operations on components of the human immune system. British Journal of Surgery 72, 771-776.

Livingston, D. H. \& Malangoni, M. A. (1989). An experimental study of the susceptibility to infection after haemorrhagic shock. Surgery, Gynaecology \& Obstetrics 168, 138-142.

McIrvine, A. J. \& Mannick, J. A. (1983). Lymphocyte function in the critically ill surgical patient. Surgery Clinics of North America 63, 245-261.

Miller, G. V., Ramsden, C. W. \& Primrose, J. N. (1991). Autologous transfusion: an alternative to transfusion with banked blood during surgery for cancer. British Journal of Surgery 78, 713-715.

Neilsen, H. J., Hammer, J. H., Moesgaard, F. \& Kehlet, H. (1989). Ranitidine prevents postoperative transfusion induced depression of delayed hypersensitivity. Surgery 105, 711-717. 
Ohzato, H., Yoshizaki, K., Nishimoto, N., Ogata, A., Tagoh, H., Monden, M., Gotoh, M., Kishimoto, T. \& Mori, T. (1992). Interleukin-6 as a new indicator of inflammatory status: detection of serum levels of II-6 and CRP after surgery. Surgery 111, 201-209.

Ozmen, V., McSwain, N. E., Nichols, R. L., Smith, J. \& Flint, L. M. (1992). Autotransfusion with potentially culture positive blood (CPB) in abdominal trauma: preliminary data from a prospective study. Journal of Trauma 32, 36-39.

Pinto, V., Balonedo, R., Nicolas, C., Barez, A., Perez, A. \& Aza, J. (1991). Relationship of transfusion and infective complications after gastric carcinoma operations. Transfusion 31, 114-118.

Polk, H. C., Cheadle, W. G., Livingston, D. H., Rodriguez, J. L., Starko, K. M., Izu, A. E., Jaffe, H. S. \& Sonnenfeld, G. (1992). A randomised prospective trial to determine the efficacy of Interferon gamma in severely injured patients. American Journal of Surgery 163, 191-196.

Pullicino, E. A., Carli, F., Poole, S., Rafferty, B., Malik, S. T. A. \& Elia, M. (1990). The relationship between the circulating concentrations of interleukin-6 (IL-6), tumour necrosis factor (TNF) and the acute phase response to elective surgery and accidental injury. Lymphokine Research 9, 231-238.

Sedman, P. C., Ramsden, C. W., Brennan, T. G., Giles, G. R. \& Guillou, P. J. (1988). Effects of low dose perioperative interferon on the surgically induced suppression of antitumour immune responses. British Journal of Surgery 75, 976-981.

Shelby, J., Marushack, M. M. \& Nelson, E. W. (1987). Prostaglandin production and suppressor cell induction in transfusion induced immune suppression. Transplantation 43, 113-116.

Shenkin, A., Fraser, W. D., Series, J., Winstanley, F. P., McCartney, A. C., Burns, H. J. G. \& van Damme, J. (1989). The serum interleukin-6 response to elective surgery. Lymphokine Research 8, 123-127.

Sieunarine, K., Wetherall, J., Lawrence-Brown, M. M. D., Goodman, M. A., Prendergast, F. J. \& Hellings, M. (1991). Levels of complement factor C3 and its activated product, C3a, in intraoperatively salvaged blood. Australia \& New Zealand Journal of Surgery 61, 302-305.

Stephen, R. N., Kupper, T. S., Geha, A. S., Baue, A. E. \& Chaudry, I. H. (1987). Haemorrhage without tissue trauma produces immunosuppression and enhances susceptibility to infection. Archives of Surgery $122,62-68$.

Tadros, T., Wobbes, T. \& Hendriks, T. (1992). Blood transfusion impairs the healing of experimental intestinal anastomoses. Annals of Surgery 215, 276-281.

Tartter, P. I. (1989). Blood transfusions and post operative infections. Transfusion 29, 456-459.

Tartter, P. I., Heinmann, T. M. \& Aufses, A. H. (1986). Blood transfusion skin test reactivity and lymphocytes in inflammatory bowel disease. American Journal of Surgery 151, 358-361.

Teodorczyk-Injeyan, J. A., Sparkes, B. G., Mills, G. B., Falk, R. E. \& Peters, W. J. (1987). Impaired expression on interleukin-2 receptor (IL-2R) in the immunosuppressed burned patient: reversal by exogenous IL-2. Journal of Trauma 27, 180-187.

Tonnesen, E. (1989). Immunological aspects of anaesthesia and surgery - with special reference to NK cells. Danish Medical Bulletin 36, 263-281.

Tosatu, G. \& Jones, K. D. (1990). Interleukin-1 induces interleukin-6 production in peripheral blood monocytes. Blood 75, 1305-1310.

Utoh, J., Yamamoto, T., Utsunomiya, T., Kambara, T., Goto, H. \& Myauchi, T. (1988). Effect of surgery on neutrophil functions, superoxide and leukotriene production. British Journal of Surgery 75, 682-685.

Vantwuyver, E., Mooijaart, R. J. D., Tenberge, I. J. M., Vanderhorst, A. R., Wilmink, J. M., Kast, W. M., Melief, C. J. M. \& Dewaal, L. P. (1991). Pretransplant transfusion revisited. New England Journal of Medicine 325, 1210-1213.

Waymack, J. P., Fernandes, G., Yurt, R. W., Venkatraman, J. T., Burleson, D. G., Guzman, R. F., Mason, A. D. Jr \& Pruitt, B. A. Jr (1990). Effect of blood transfusion on immune function. Part VI. Effect on immunologic response to tumour. Surgery 108, 172-178.

Waymack, J. P., Gallon, L., Barcelli, U., Trocki, O. \& Alexander, J. W. (1987). Effect of blood transfusion on immune function III. Alterations in macrophage arachidonic acid metabolism. Archives of Surgery 122, 56-60.

Waymack, J. P., Rapien, J., Garnet, D., Tweddell, J. S. \& Alexander, J. W. (1986). Effect of transfusion on immune function in a traumatized animal model. Archives of Surgery 121, 50-56.

Younes, R. N., Rogatko, A., Vydelingum, N. A. \& Brennan, M. F. (1991). Effect of hypovolaemia and transfusion in MCA tumour bearing rats. Surgery 109, 307-312. 